\title{
Gynaecological problems and choices for contraception in women with inherited bleeding disorders
}

\author{
Claire Burton, Claudia Chi, Rezan Kadir
}

\section{Introduction}

Inherited bleeding disorders (IBDs) in women are more common than previously suspected. Women with IBDs are at risk of heavy bleeding from haemostatic challenges such as menstruation and childbirth. These common haemostatic challenges can cause symptoms even in mildly affected women, thus increasing the clinical prevalence of IBDs in women compared to men. ${ }^{1}$

von Willebrand disease (VWD) is the most common IBD. This has a reported prevalence in the general population of $0.8-1.3 \% .^{2,3}$ It is an autosomal disorder resulting from defects in von Willebrand factor (VWF), a protein necessary for haemostasis and an integral part of platelet adhesion and thrombus formation. VWF also acts as a carrier for factor VIII (an essential clotting factor) in the circulation. ${ }^{4}$

VWD can be a result of a quantitative (Types 1 and 3) or qualitative (Type 2) defect. Type I VWD accounts for $70 \%$ of all cases with considerable variation in severity. The majority of cases are mild and patients may remain asymptomatic until times of haemostatic challenges such as major trauma or surgery.5 Type 2 VWD accounts for $15-20 \%$ of cases and is characterised by abnormal structures of VWF that affect interaction between platelets, vessel walls and VWF. Type 3 VWD is the least common but most severe form of the disease. It is an autosomalrecessive disorder characterised by a severe deficiency of VWF and factor VIII.

Haemophilia A and B are X-linked IBDs characterised by deficiencies of clotting factor VIII or IX, respectively. Men inherit the condition whilst women are affected as carriers. The incidence of haemophilia A and B in the general population is 1 in 10000 and 1 in 60000 , respectively, ${ }^{6}$ but the carrier rates in women are unknown. A wide range of factor VIII or IX levels have been reported among carriers of haemophilia, from the upper limit of normal through to very low levels similar to affected males caused by random $\mathrm{X}$-chromosome inactivation (lyonisation). ${ }^{7}$ Thus carriers may have an increased bleeding tendency and experience significant bleeding symptoms. In a study by Plug et al. carriers were found to experience more spontaneous and provoked haemorrhage compared to non-carriers in families with haemophilia. ${ }^{8}$

J Fam Plann Reprod Health Care 2008; 34(2): 93-98

(Accepted 18 September 2007)

Department of Obstetrics and Gynaecology, Royal Free Hospital, London, UK

Claire Burton, DFSRH, MRCOG, Specialist Registrar

Department of Obstetrics and Gynaecology and Haemophilia Centre and Haemostasis Unit, Royal Free Hospital, London, UK

Claudia Chi, MBBS, DFSRH, Specialist Registrar

Rezan Kadir, MRCOG, MD, Consultant Obstetrician and Gynaecologist

Correspondence to: Dr Rezan Kadir, Department of Obstetrics and Gynaecology, Royal Free Hospital, Pond Street, London NW3 2QG, UK. E-mail: rezan.abdul-kadir@royalfree.nhs.uk
Factor XI deficiency is a rare autosomal disorder but is more frequently seen in Jewish communities with carrier rates as high as $9 \%$ in Ashkenazi Jews. ${ }^{9}$ This condition is associated with a variable bleeding tendency that does not seem to correlate with factor XI levels; hence both heterozygotes and homozygotes may be symptomatic. ${ }^{10}$ Inherited platelet dysfunction and other factor deficiencies are very rare disorders requiring specialised care and are beyond the remit of this review.

\section{Menorrhagia and IBDs}

Menorrhagia (heavy menstrual bleeding) is a common gynaecological complaint. Causes of menorrhagia may be local (e.g. uterine or pelvic pathology) or systemic (e.g. liver disease, hypothyroidism or haemostatic disorders). However, no cause is identified in over $50 \%$ of cases, which has been described as dysfunctional uterine bleeding (DUB). Haemostasis during menstruation is a complex process with the formation of a haemostatic plug playing a pivotal role. ${ }^{11}$ It is therefore unsurprising that menorrhagia is the most commonly seen bleeding problem in women with coagulation disorders and may be the first sign of an underlying disorder. ${ }^{12,13}$ Similarly, an undiagnosed IBD can be an underlying cause or a precipitating factor in a significant proportion of women diagnosed with DUB.

Women with IBDs are likely to suffer with heavy menstrual bleeding. In a study by Kadir et al., $67 \%$ of 95 women with various IBDs had menorrhagia compared to $29 \%$ of the controls. ${ }^{14}$ The majority (74-95\%) of women with known VWD report menorrhagia. ${ }^{13-16}$ Menorrhagia has also been reported in 50-60\% of women with rarer factor deficiencies. ${ }^{14,17}$

Women with IBDs also suffer from prolonged menstruation. Bleeding for more than 8 days was reported in $25 \%$ of women with these disorders compared to $4 \%$ in the control group. ${ }^{14}$ Women with IBDs bleed heavily throughout menstruation in contrast to women with menorrhagia in general where $90 \%$ of the total menses is lost in the first 3 days. ${ }^{18}$

\section{Adolescents with menorrhagia}

Adolescent menorrhagia has long been recognised to be associated with IBD, especially among those with acute menorrhagia requiring hospital admission. Clinicians are more likely to consider testing for coagulation disorders in young girls compared to adults with menorrhagia. ${ }^{19}$ Studies of adolescent populations with menorrhagia have shown the prevalence of IBDs to be $10-57 \% .^{20,21}$ Strong predictors include menorrhagia from menarche, menorrhagia requiring hospital admission and a family history of bleeding symptoms..$^{22,23}$ Menstruation may be the first haemostatic challenge affected girls face and bleeding can be severe. The first case of VWD described by Erik von Willebrand was a young girl who died of uncontrolled menstrual bleeding at the age of 13 years. ${ }^{24}$ Therefore, testing for coagulation disorders is important in these girls, especially those with profound menorrhagia at menarche and requiring hospital admission. The American College of Obstetricians and Gynecologists (ACOG) recommends screening for VWD in adolescents presenting with severe menorrhagia. 25 


\section{Women with menorrhagia}

It has been assumed that IBDs are a rare cause of menorrhagia in adults. Clinicians rarely test for IBDs when managing women with menorrhagia, 19 therefore this potential diagnosis is often overlooked. In a study of 150 women referred to a gynaecology clinic with menorrhagia, $26(17 \%)$ were diagnosed with an IBD. The majority $(13 \%)$ had VWD, the commonest IBD. ${ }^{26}$ A systematic review of 11 studies comprising 988 women with menorrhagia showed an overall prevalence of VWD of $13 \%$ (range 5-24\%). ${ }^{27}$ Platelet disorders and factor deficiencies are less common but have also been identified in women with menorrhagia. ${ }^{26,28,29}$ Therefore IBDs should be borne in mind when investigating women with menorrhagia.

There is currently no consensus on whether testing for IBDs should be part of routine investigation for women presenting with menorrhagia. The National Institute for Health and Clinical Excellence (NICE) guidelines recommend testing for coagulation disorders if the woman has had heavy menstrual bleeding from menarche and a personal or family history suggestive of an IBD. ${ }^{30}$ The ACOG recommend screening for VWD in adolescents with menorrhagia, in adults when pelvic pathology has been excluded and in all women prior to surgical treatment. A comprehensive personal and family bleeding history can be used as a screening tool to identify women who are more likely to have an underlying IBD. Kouides et al. have proposed a screening procedure for selecting those women who require further testing for IBDs (Box 1). 31

Testing for IBDs should also be considered in women who fail to respond to medical management and who continue to have heavy periods with the levonorgestrel intrauterine system (LNG IUS) or after endometrial ablation.

Menstrual blood loss can be assessed using a pictorial blood assessment chart (PBAC). The number and saturation of used sanitary products are recorded and a score is then generated. A score of greater than 100 has a reported sensitivity and specificity of over $80 \%$ for menorrhagia defined as greater than $80 \mathrm{ml}$ blood loss. 32 The validity of PBAC has been questioned because of a wide variation in its specificity and sensitivity for diagnosis of menorrhagia in different studies. ${ }^{18,33-35}$ However, it is a simple non-invasive tool that can be helpful in clinical practice for the initial assessment and monitoring of treatment.

\section{Management of menorrhagia}

Women with IBDs and menorrhagia should be managed in a multidisciplinary setting that includes both a gynaecologist and a haematologist. ${ }^{35}$ Haemophilia treatment centres have been associated with strong positive feedback from patients. They also allow for onsite haemostasis testing that can reduce misdiagnosis. 36,37

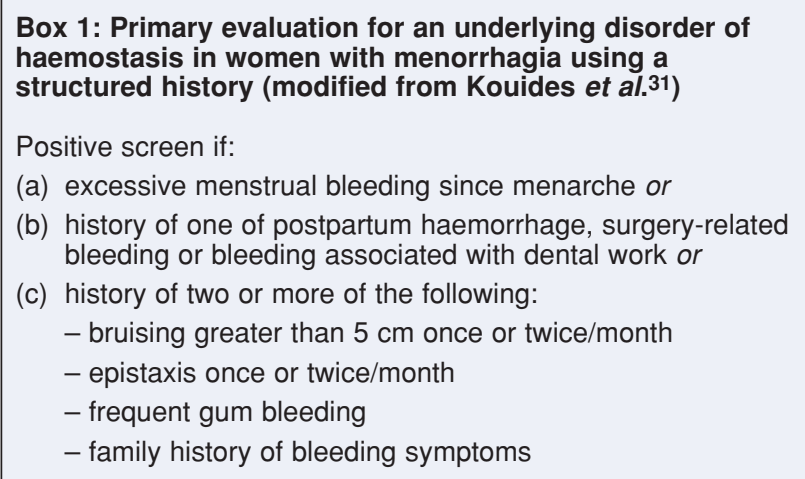

Menorrhagia in women with IBDs is likely to be due to a clotting factor deficiency. However, pelvic pathology may co-exist with an IBD. ${ }^{37}$ Therefore, individuals should have appropriate gynaecological assessment to exclude local causes, especially the possibility of malignancy in older women.

Options for management include medical treatments [tranexamic acid, the combined oral contraceptive (COC) pill, desmopressin and the LNG IUS] and surgical treatments (endometrial ablation or hysterectomy). Management will be dependent on the patient's age, fertility status and wishes.

\section{Medical treatments}

Tranexamic acid is an anti-fibrinolytic agent that significantly reduces plasminogen activator and plasmin activity thus reducing fibrinolysis. It reduces menstrual blood loss by up to $59 \%$ in women with idiopathic menorrhagia. ${ }^{38}$ Oral tranexamic acid is usually well tolerated but side effects include nausea, headache and diarrhoea. Tranexamic acid should be used for 3 months initially and can be continued indefinitely if successful..$^{30}$ The recommended dose is $1 \mathrm{~g}$ taken three to four times a day for 3-4 days. Tranexamic acid has also been widely used in patients with IBDs to control or prevent epistaxis, oral cavity and gastrointestinal bleeding.

In women with menorrhagia and no IBD non-steroidal anti-inflammatory drugs (NSAIDs) can be effective in reducing blood loss, menstrual pain and migraine. However, their anti-aggregator effect on platelets means they should not be used in women with an IBD. This highlights the need for diagnosis before treatment. 35

Combined oral contraceptives (COCs) provide reliable birth control and cycle control as well as reducing dysmenorrhoea and menstrual blood loss. ${ }^{39}$ In women with IBDs, COCs are widely used for menorrhagia. However, there is a lack of objective data on their efficacy in reducing menstrual blood loss. In a survey of Type 2 and 3 VWD, $88 \%$ of 25 women treated with COCs reported that they were effective. ${ }^{40}$ In Type 1 VWD, COCs were effective in $24-37 \%$ of women. ${ }^{15}$ Continuous use (2-3 monthly) of COCs rather than 21-day courses may be beneficial in allowing women to control the timing and frequency of menstruation as well as menstruation-associated symptoms. ${ }^{41}$ This regime can be especially useful in adolescents with menorrhagia that is affecting their quality of life and school attendance or performance. Serious side effects of COCs include hypertension, liver dysfunction and thrombosis. Women with IBDs, however, have a low inherited thrombotic risk. Other side effects include nausea, headache, breast tenderness, breakthrough bleeding, skin reactions and depression.

Desmopressin (DDAVP ${ }^{\circledR}, 1$-desamino-8-D-arginine vasopressin) is a synthetic analogue of vasopressin. It increases plasma concentrations of factor VIII and VWF and increases platelet adhesiveness. ${ }^{42,43}$ It is particularly effective in patients with Type 1 VWD and mild to moderate haemophilia A. A test dose is recommended to identify responders prior to treatment. DDAVP can be given by intravenous or subcutaneous injection or intranasally as a spray. The latter formulation is ideal for home use without delay or use of needles. Side effects are related to a vasomotor effect, namely tachycardia, flushing and headache. With repeated doses there is a small risk of hyponatraemia and water intoxication due to an antidiuretic effect.

Case series have shown a positive subjective response to DDAVP in women with IBDs and menorrhagia; $86 \%$ and $92 \%$ of these women treated with subcutaneous and 
intranasal DDAVP, respectively, reported a good or excellent response. 44,45 In a randomised trial using PBAC scores to assess menstrual loss there was a significant reduction in PBAC score with DDAVP treatment compared to pretreatment but this was not significant when compared to placebo. ${ }^{46}$ In the management of menorrhagia, DDAVP is usually given as a once-daily nasal spray for the first 2-3 days of the cycle. Women with IBDs may experience heavy flow throughout the menses and therefore dosing and duration should be individualised. Recent evidence suggests that the use of DDAVP in conjunction with tranexamic acid may be more effective in reducing menstrual loss in these women. ${ }^{47}$

Oral progestogens can be used for the treatment of menorrhagia when given as a 21-day course (Days 5-26). Luteal phase progestogens (for 7-10 days) have no effect on menstrual blood loss. In a study by Irvine et al., both $21-$ day course progestogens and the LNG IUS were associated with a significant and comparable reduction $(87 \%$ and $94 \%$, respectively) in menstrual blood loss at 3 months. 48 However, the LNG IUS was associated with higher rates of satisfaction (64\% vs 44\%) and continuation with treatment (77\% vs 44\%). Compliance is usually poor with oral progestogens due to side effects such as fatigue, mood changes, weight gain, bloating, depression and irregular bleeding. In women with IBDs, high-dose oral progestogens can be used with DDAVP or clotting factors in the treatment of acute menorrhagia. More research is needed into the therapeutic effects of injectable progestogens and implants on menorrhagia in general and in women with IBDs.

Gonadotrophin-releasing hormone (GnRH) analogues are effective at reducing menstrual flow and duration. Hypo-estrogenic side effects and cost prohibit their longterm use but they may be an alternative option to surgery for young women with resistant menorrhagia and severe IBDs. If used for more than 6 months, add-back hormone replacement therapy should be used to counteract low estrogen levels. ${ }^{37}$

The $L N G$ IUS (Mirena ${ }^{\circledR}$ ) is highly effective in reducing menstrual blood loss (range 74-97\%).49 It is also an effective and reversible method of contraception, making it an ideal treatment for women with menorrhagia who wish to preserve their fertility. However, the discontinuation rate was as high as $20 \%$ in randomised controlled trials due to irregular bleeding, expulsion or systemic progestogenic side effects. 49 Appropriate counselling and patient education may increase its tolerance and acceptability.

There are limited data regarding the use of the LNG IUS in women with IBDs. In a group of 16 women with these disorders, their PBAC scores dropped from a median of 213 to 47,9 months after LNG IUS insertion. Nine women reported amenorrhoea and no side effects other than irregular spotting were reported.50 This treatment method should be considered prior to any surgical management as these women are at increased risk of bleeding complications. There is a potential risk of bleeding at the time of IUS insertion; hence haemostatic coverage may be required in some women, particularly those with severe forms of IBDs. ${ }^{35}$

Clotting factor replacement may be required during menstruation in some women, especially those with severe factor deficiencies. A multidisciplinary approach to management is of paramount importance in such cases.

\section{Surgical treatment}

Surgery may be required in the presence of pelvic pathology, for women who do not tolerate medical treatment or in whom this is unsuccessful. Women with
IBDs are more likely to have both intraoperative and delayed (7-10 days later) bleeding complications, even with relatively minor procedures such as hysteroscopy and biopsy. A multidisciplinary team approach is essential involving a haematologist, gynaecologist and anaesthetist. Prophylactic treatment can be given preoperatively to reduce the risk of excessive bleeding. An experienced gynaecologist should perform the surgery with meticulous attention to haemostasis and the use of surgical drains should be considered. Postoperative follow-up may be required to monitor factor levels and to identify delayed bleeding problems. ${ }^{37}$

Previously, hysterectomy has been the mainstay of management of menorrhagia and still provides the definitive treatment with high patient satisfaction. However, it is associated with an overall $3.5 \%$ operative and $9 \%$ postoperative complication rates and a mortality rate of 0.38 per 1000.51 Long-term risks include early ovarian failure, pelvic pain, sexual dysfunction and urinary problems.

Increasingly, endometrial ablation techniques are used as an alternative to hysterectomy. Although they are not as effective as hysterectomy in reducing menstrual blood loss and improving patient satisfaction, they have a shorter operating time, quicker recovery period and lower complication rate. 52 They may be performed under local anaesthetic and are usually possible as a day case. Firstgeneration techniques (i.e. resection, laser and rollerball) are performed under hysteroscopic control. Secondgeneration techniques are mostly performed blindly and involve the use of energy (heat, cold or microwave) to ablate the full thickness of the endometrium. These techniques are simpler and faster to perform than firstgeneration techniques whilst patient satisfaction rates and reduction in menstrual blood loss are similar. ${ }^{53}$ As secondgeneration techniques are less invasive and thus have a lower risk of bleeding complications they may be more suitable for women with IBDs. ${ }^{35}$ However, there are limited data on their use in such women. In a small retrospective study of seven women with VWD-related menorrhagia, all the women reported a positive short-term effect, but four experienced a recurrence of menorrhagia at a median of 8 months with three undergoing hysterectomy within a year post-ablation..$^{54}$ The techniques used included endometrial resection (3), rollerball (1), thermal (1), electrocautery (1) and balloon ablation (1). All the women received prophylactic treatment preoperatively and no bleeding complications were reported. Higher efficacy of endometrial ablation in women with coagulopathy was reported in two other retrospective studies. 55,56 Toth et al. ${ }^{55}$ evaluated thermal balloon ablation in 70 women with severe menorrhagia and systematic disease, including 25 women with coagulopathy. Their study showed a success rate of over $90 \%$ at 3-year post-thermal balloon ablation. El-Nashar et al. ${ }^{56}$ evaluated the use of thermal balloon or bipolar radio frequency ablation techniques in 41 women with various coagulopathies. The authors reported similar efficacy between the coagulopathy group and the reference group (5\% vs $7 \%$ hysterectomy or re-ablation rate at a median follow-up of 24.8 months).

\section{Dysmenorrhoea}

Moderate to severe dysmenorrhoea has been reported in half of the women with IBDs attending a haemophilia centre. 57 Women with IBDs seem to be more severely affected with dysmenorrhoea than controls, possibly due to the increased prevalence of menorrhagia in this group of women. Early recognition, accurate diagnosis and appropriate management will help to improve not only the 
standard of care but also the quality of life for these women. Treatment would usually involve NSAIDs but these should be avoided in women with IBDs because of their anti-platelet activity. Alternative analgesia such as paracetamol and codeine-based products may be used. Use of COCs may help reduce dysmenorrhoea, as may the LNG IUS. Surgery may be required if underlying pathology is found.

\section{Haemorrhagic ovarian cysts}

A variable degree of bleeding may occur during ovulation. This may be associated with abdominal/pelvic pain (mittelschmerz). Women with IBDs are more likely to have significant bleeding at ovulation leading to pain, haemorrhagic ovarian cysts, broad ligament haematomas or even haemoperitoneum. ${ }^{35}$ In a survey of 81 women with Type 1 VWD, 60 reported mid-cycle pain similar in intensity to their period pain. ${ }^{15}$ There have been many case series of haemorrhagic cysts in women with IBDs with a prevalence ranging from $2 \%$ to $25 \% .58$ Although haemorrhagic cysts can be treated surgically, conservative treatment with or without the use of clotting factors is preferential in these women. ${ }^{37}$ COCs prevent ovulation and therefore can be used to reduce mid-cycle pain and the formation of haemorrhagic cysts. 59,60

\section{Other gynaecological problems}

A survey of 102 women with VWD showed a higher prevalence of pelvic pathology in women with IBDs compared to controls, including endometriosis (30\% vs $13 \%)$ endometrial hyperplasia (10\% vs $1 \%)$, fibroids $(32 \%$ vs $17 \%$ ) and endometrial polyps (8\% vs $1 \%) .{ }^{16}$ It is doubtful that women with IBDs are more likely to develop these pathologies, but as these conditions often present with bleeding, women with IBDs are more likely to be symptomatic. ${ }^{35}$ Further studies are required to assess the prevalence and severity of these gynaecological conditions in women with IBDs.

\section{Quality of life}

Menorrhagia and dysmenorrhoea have a significant impact on a woman's quality of life, disrupting and limiting many aspects of her usual activities. In a study by Kadir et al., women with IBDs had a significantly worse quality of life during menstruation compared to controls. ${ }^{57}$ More than one-third reported taking time off work or school during menstruation. They also accomplished less and more experienced difficulties performing their work. A high prevalence of iron deficiency anaemia has been reported in women with VWD and this may further affect cognitive functioning. ${ }^{17,61}$

\section{Contraception}

When considering methods of contraception in women with IBDs the individual's requirements and wishes must be considered together with their menstrual pattern as well as medical and social factors. Options for women with IBDs who fulfil the World Health Organization (WHO) Medical Eligibility Criteria for Contraceptive Use 62 are the same as for women without IBDs. However, the risks and benefits of various contraceptive options may be different in this group of women, hence individualised assessment is required.

Barrier methods such as condoms provide 95-98\% effective contraception with consistent correct use with the added advantage of reducing the risk of transmission of sexually transmitted diseases. ${ }^{63}$ Barrier methods can also be used in conjunction with other forms of contraception.

COCs (available as a pill or patch) may be beneficial in women who complain of menorrhagia and dysmenorrhoea. Women who suffer mid-cycle pain or recurrent haemorrhagic cysts may also benefit from COC use. Therefore, COCs can be an ideal choice for women with IBDs who have a low inherent thrombotic risk and in whom there is a higher prevalence of these gynaecological problems.

The progestogen-only pill is associated with irregular bleeding, which may have a negative impact on quality of life especially if bleeding is heavy.

Depot medroxyprogesterone acetate may be a better contraceptive choice as it is reported to induce amenorrhoea in almost $60 \%$ of users by 12 months. However, its effect on the menstrual pattern is unpredictable. Users should also be aware of a potential delay in return to fertility of a median of 9 months from the date of their last injection.

The long-acting progestogen implant provides effective contraception, but like other progestogen-only methods carries a risk of irregular bleeding. In one study of 106 users, 24 had it removed prematurely for this reason. ${ }^{64}$ There is also a risk of localised bleeding at the time of insertion and removal in women with IBDs. Haemostatic cover should be considered in consultation with the local haemophilia centre to minimise this risk.

Intrauterine devices (IUDs) provide effective contraception for at least 5 years at a time. Coppercontaining IUDs prevent fertilisation by acting on the endometrium and creating an environment unsupportive for a pregnancy. Women should be informed that menstrual abnormalities are common in the first 3-6 months after insertion including spotting, heavier or longer menstruation. This usually settles over time but may be a problem in women with IBDs. Hence the IUD is not a contraceptive of choice in these women, especially those with pre-existing heavy menstrual loss. Tranexamic acid can be used concomitantly and is effective in reducing menstrual blood loss in association with IUD use. ${ }^{65}$ The $L N G I U S$ is a more suitable long-acting method of contraception for women with menorrhagia including those with IBDs. As it works primarily on the endometrium to prevent implantation, most women will continue to ovulate and may therefore continue to experience mid-cycle pain and haemorrhagic cysts. This should be borne in mind in women with severe bleeding disorders and a previous history of significant bleeding during ovulation. COCs could be used in addition to the LNG IUS to control this complication. There is some evidence of increased ovarian cyst formation with the use of copper-containing IUDs or the LNG IUS, ${ }^{66}$ but these cysts are mostly asymptomatic and resolve spontaneously. The risk of expulsion is 1 in 20 and of perforation less than 1 in 1000. There is a small risk of bleeding at the time of insertion, hence haemostatic cover may be required for some women especially those with severe clotting factor deficiencies.

Levonorgestrel tablets (Levonelle ${ }^{\circledR}$ ) or the insertion of a copper-containing IUD could be used in women requiring emergency contraception. Levonelle is preferable if the woman presents within 72 hours of unprotected intercourse. It may still be considered between 73 and 120 hours, but this is outside the product licence and women should be informed of the limited evidence of its efficiency in such circumstances. ${ }^{67}$ A copper IUD can be inserted up to 5 days after the first episode of unprotected intercourse. In women with IBDs, the risk of heavy menstrual blood loss associated with copper IUD should be discussed and tranexamic used concomitantly to prevent this complication.

Women with IBDs who request sterilisation should be 
made aware of the increased bleeding risks with surgery. In a series of nine cases of laparoscopic sterilisation, one woman required a mini-laparotomy and salpingectomy to control bleeding from the Fallopian tube. Another patient developed a wound haematoma. ${ }^{14}$ Alternative methods of contraception should be discussed including the LNG IUS and male sterilisation.

\section{Summary}

Women with IBDs are at risk of the same gynaecological problems that affect all women. However, they are more likely to be symptomatic of conditions that present with bleeding. Menorrhagia has been well recognised as a common symptom among these women. They may also be more likely to have significant bleeding at ovulation leading to pain, haemorrhagic cysts and even haemoperitoneum. Therapeutic options for menorrhagia are similar to those for women in general, but women with IBDs may need specific treatment such as DDAVP and clotting factor replacement. They are at increased risk of bleeding with surgical interventions and require additional monitoring of the haemostatic parameters. Therefore, a multidisciplinary approach, including both a haematologist and gynaecologist, is essential in the management of these women. Contraceptive choices for women with IBDs who fulfil the WHO Medical Eligibility Criteria for Contraceptive Use $e^{62}$ are the same as for women without such disorders. However, options associated with a risk of increased bleeding are best avoided and haemostatic cover should be considered when using invasive methods.

\section{Statements on funding and competing interests \\ Funding None identified.}

Competing interests None identified.

\section{References}

1 Federici AB, Mannuccci PM. Actual management of von Willebrand disease: first report on 880 cases of the Italian registry of VWD. Blood 1997; 90: 33a.

2 Rodeghiero F, Castaman G, Dini E. Epidemiological investigation of the prevalence of von Willebrand's disease. Blood 1987; 69: 454-459.

3 Werner EJ, Broxson EH, Tucker EL, Giroux DS, Shults J, Abshire TC. Prevalence of von Willebrand's disease in children: a multiethnic study. J Pediatr 1993; 123: 893-898.

4 Weiss HJ, Sussman II, Hoyer LW. Stabilization of factor VIII in plasma by the von Willebrand factor. Studies on post transfusion and dissociated factor VIII and in patients with von Willebrand's disease. J Clin Invest 1977; 60: 390-404.

5 Ruggeri ZM. Pathogenesis and classification of von Willebrand disease. Haemostasis 1994; 24: 265-275.

6 Tuddenham EGD, Cooper DN. The Molecular Genetics of Haemostasis and its Inherited Bleeding Disorders (Oxford Monographs in Medical Genetics No. 25). Oxford, UK: Oxford University Press, 1994.

7 Lyon MF. Sex chromatin and gene action in the mammalian Xchromosome. Am J Hum Genet 1962; 14: 135-148.

8 Plug I, Mauser-Bunschoten E, Brocker-Vriends A, et al. Bleeding in carriers of haemophilia. Blood 2006; 108: 52-56.

9 Shpilberg O, Peretz H, Zivelin R, et al. One of the two common mutations causing factor XI deficiency in Ashkenazi Jews (type II) is also prevalent in Iraqi Jews, who represent the ancient gene pool of Jews. Blood 1995; 85: 429-432.

10 Bolton-Maggs PHB, Young-Wan-Yin B, McCraw AH, Slack J, Kernoff PBA. Inheritance and bleeding in factor XI deficiency, Br J Haematol 1988; 69: 521-528.

11 Christiaens GC, Sixma JJ, Haspels AA. Haemostasis in the menstrual endometrium: a review. Obstet Gynaecol Surv 1982; 37: 281-303.

12 Edlund M, Blomback M, von Schoultz B, Andersson O. On the value of menorrhagia as a predictor of coagulation disorders. Am J Hematol 1996; 53: 234-238.

13 Ragni MV, Bontempo FA, Hassett AC. Von Willebrand disease and bleeding in women. Haemophilia 1999; 5: 313-317.

14 Kadir RA, Economides DL, Sabin CA, Pollard D, Lee CA Assessment of menstrual blood loss and gynaecological problems in patients with inherited bleeding disorders. Haemophilia 1999; 5: 40-48.
15 Kouides PA, Phatak PD, Burkart P, et al. Gynaecological and obstetrical morbidity in women with type I von Willebrand disease: results of a patient survey. Haemophilia 2000; 6: 643-648.

16 Kirtava A, Drews C, Lally C, Dilley A, Evatt B. Medical, reproductive and psychosocial experiences of women diagnosed with von Willebrand's disease receiving care in haemophilia treatment centres: a case-control study. Haemophilia 2003; 9: 292-297.

17 Lukes AS, Kadir RA, Peyvandi F, Kouides PA. Disorders of haemostasis and excessive menstrual bleeding: prevalence and clinical impact. Fertil Steril 2005; 84: 1338-1344.

18 Janssen CA, Scholten PC, Heintz AP. A simple visual assessment technique to discriminate between menorrhagia and normal menstrual blood loss. Obstet Gynecol 1995; 85: 977-982.

19 Chi C, Shiltagh N, Kingman CEC, Economides DL, Lee CA, Kadir RA. Identification and management of women with inherited bleeding disorders: a survey of obstetricians and gynaecologists in the United Kingdom. Haemophilia 2006; 12: 405-412.

20 Bevan JA, Maloney KW, Hillery CA, Gill JC, Montgomery RR, Scott JP. Bleeding disorders: a common cause of menorrhagia in adolescents. J Pediatr 2001; 138: 856-861.

21 Jayasinghe $\mathrm{Y}$, Moore $\mathrm{P}$, Donath $\mathrm{S}$, Campbell J, Monagle $\mathrm{P}$, Grover S. Bleeding disorders in teenagers presenting with menorrhagia. Aust N Z J Obstet Gynaecol 2005; 45: 439-443.

22 Claessens EA, Cowell CA. Acute adolescent menorrhagia. Am J Obstet Gynecol 1981; 139: 277-280

23 Smith YR, Quint EH, Hertzberg RB. Menorrhagia in adolescents requiring hospitalisation. I Pediatr Adolesc Gynecol 1998; 11: 13-15.

24 Nilsson IM. Von Willebrand's disease - fifty years old. Acta Med Scand 1977; 201: 497-508.

25 ACOG Committee on Gynecologic Practice. Committee Opinion: Number 263, December 2001. von Willebrand's disease in gynecologic practice. Obstet Gynecol 2001; 98: $1185-1186$.

26 Kadir RA, Economides DL, Sabin CA, Owens D, Lee CA. Frequency of inherited bleeding disorders in women with menorrhagia. Lancet 1998; 351: 485-489.

27 Shankar M, Lee CA, Sabin CA, Economides DL, Kadir RA. Von Willebrand disease in women with menorrhagia: a systematic review. Br J Obstet Gynaecol 2004; 111: 734-740.

28 Philipp CS, Dilley A, Miller $\mathrm{CH}$, et al. Platelet functional defects in women with unexplained menorrhagia. J Thromb Haemost 2003; 1 : 477-484.

29 Dilley A, Drews C, Miller C, et al. von Willebrand disease and other inherited bleeding disorders in women with diagnosed menorrhagia. Obstet Gynecol 2001; 97: 630-636.

30 National Institute for Health and Clinical Excellence (NICE). Heavy Menstrual Bleeding. (Clinical Guidance 44). 2007. http://www.nice.org.uk/CG44 [Accessed 15 July 2007]

31 Kouides PA, Conard J, Peyvandi F, Lukes A, Kadir RA. Hemostasis and menstruation: appropriate investigation for underlying disorders of hemostasis in women with excessive menstrual bleeding. Fertil Steril 2005; 84: 1345-1351.

32 Higham JM, O'Brien PM, Shaw RW. Assessment of menstrual blood loss using a pictorial chart. Br J Obstet Gynaecol 1990; 97: 734-739.

33 Reid PC, Coker A, Coltart R. Assessment of menstrual blood loss using a pictorial chart: a validation study. $\mathrm{Br} J$ Obstet Gynaecol 2000; 107: 320-322.

34 Wyatt KM, Dimmock PW, Walker TJ, O'Brien PM. Determination of total menstrual blood loss. Fertil Steril 2001; 76: $125-131$

35 Lee CA, Chi C, Pavord SR, Bolton-Maggs PHB, Pollard D, Hinchcliffe-Wood A, et al. The obstetric and gynaecological management of women with inherited bleeding disorders review with guidelines produced by a taskforce of UK Haemophilia Centre Doctors' Organisation. Haemophilia 2006; 12: $301-336$.

36 Khan A, Pollard D, Lee CA, Kadir RA. A first year clinical review of the multidisciplinary haemophilia/obstetric and gynaecology clinic at the Royal Free Hospital Haemophilia Centre. Haemophilia 2004; 10(Suppl. 3): 143-145.

37 Kadir RA, Lukes AS, Kouides PA, Fernandez H, Goudemand J. Management of excessive menstrual bleeding in women with hemostatic disorders. Fertil Steril 2005; 84: 1352-1359.

38 Wellington K, Wagstaff AJ. Tranexamic acid: a review of its use in the management of menorrhagia. Drugs 2003; 63: 1417-1433

39 Callard GV, Litovsky FS, DeMerre LJ. Menstruation in women with normal or artificially controlled cycles. Fertil Steril 1966; 17: 684-688. 
40 Foster PA. The reproductive health of women with von Willebrand disease unresponsive to DDAVP: results of an international survey. On behalf of the Subcommittee on von Willebrand Factor of the Scientific and Standardization Committee of the ISTH. Thromb Haemost 1995; 74: 784-790.

41 Edelman AB, Gallo MF, Jensen JT, Nichols MD, Schulz KF, Grimes DA. Continuous or extended cycle vs. cyclic use of combined oral contraceptives for contraception. Cochrane Database Syst Rev 2005; (3): CD004695.

42 Lethagen S, Harris AS, Sjorin E, Nilsson IM. Intranasal and intravenous administration of desmopressin: effect on FVIII/vWF, pharmacokinetics and reproducibility. Thromb Haemost 1987; 58: 1033-1036.

43 Mannucci PM, Aberg M, Nilsson IM, Robertson B. Mechanism of plasminogen activator and FVIII increase after vasoactive drugs. Br J Haematol 1975; 30: 81-93.

44 Rodeghiero F, Castaman G, Mannucci PM. Prospective multicentre study on subcutaneous concentrated desmopressin for home treatment of patients with von Willebrand disease and mild or moderate haemophilia A. Thromb Haemost 1996; 76: 692-696.

45 Leissinger C, Becton D, Cornell C Jr, Cox GJ. High-dose DDAVP intranasal spray (Stimate) for the prevention and treatment of bleeding in patients with mild haemophilia $A$, mild or moderate type 1 von Willebrand disease and symptomatic carriers of haemophilia A. Haemophilia 2001; 7: 258-266.

46 Kadir RA, Lee CA, Sabin CA, Pollard D, Economides DL. DDAVP nasal spray for treatment of menorrhagia in women with inherited bleeding disorders: a randomised placebocontrolled crossover study. Haemophilia 2002; 8: 787-793.

47 Edlund M, Blombak M, Fried G. Desmopressin in the treatment of menorrhagia in women with no common coagulation factor deficiency but with prolonged bleeding time. Blood Coagul Fibrinolysis 2002; 13: 225-231.

48 Irvine GA, Campbell-Brown MB, Lumsden MA. Randomised comparative trial of the levonorgestrel intrauterine system and norethisterone for treatment of idiopathic menorrhagia. $\mathrm{Br} \mathrm{J}$ Obstet Gynaecol 1998; 105: 592-598.

49 Stewart A, Cummins, Gold L, Jordan R, Phillips W. The effectiveness of the levonorgestrel intrauterine system in menorrhagia - a systematic review. Br J Obstet Gynaecol 2001; 108: 74-86.

50 Kingman CE, Kadir RA, Lee CA, Economides DL. The use of levonorgestrel releasing intrauterine system for the treatment of menorrhagia in women with inherited bleeding disorders. $\mathrm{Br}$ J Obstet Gynaecol 2004; 111: 1425-1428.

51 Maresh M, Metcalfe M, Mcpherson K. The VALUE national hysterectomy study: description of patients and their surgery. Br J Obstet Gynaecol 2002; 109: 302-312.

52 Lethaby A, Shepperd S, Cooke I, Farquhar C. Endometrial resection and ablation versus hysterectomy for heavy menstrual bleeding. Cochrane Database Syst Rev 2000; (2): CD000329.
53 Lethaby A, Hickey M. Endometrial destruction techniques for heavy menstrual bleeding: a Cochrane review. Hum Reprod 2002; 17: 2795-2806.

54 Rubin J, Wortman M, Kouides PA. Endometrial ablation for von Willebrand disease-related menorrhagia - experience with seven cases. Haemophilia 2004; 10: 477-482.

55 Toth D, Gervaise A, Guzel D, Fernandez H. Thermal balloon ablation in patients with multiple morbidity: 3 years follow-up. $J$ Am Assoc Gynecol Laparosc 2004; 11: 236-239.

56 El-Nashar SA, Hopkins MR, Feitoza SS, Pruthi RK, Barnes SA, Gebhart JB, et al. Global endometrial ablation for menorrhagia in women with bleeding disorders. Obstet Gynecol 2007; 109: 1381-1387

57 Kadir RA, Sabin CA, Pollard D, Lee CA, Economides DL. Quality of life during menstruation in patients with inherited bleeding disorders. Haemophilia 1998; 4: 836-841.

58 James $\mathrm{AH}$. More than menorrhagia: a review of the obstetric and gynaecological manifestations of bleeding disorders. Haemophilia 2005; 11: 295-307.

59 Jarvis RR, Olsen ME, Type I von Willebrand's disease presenting as recurrent corpus hemorrhagicum. Obstet Gynecol 2002; 99: 887-888.

60 Ghosh K, Mohanty D, Pathare AV, Jijina F. Recurrent haemoperitoneum in a female patient with type III von Willebrand's disease responded to administration of oral contraceptive. Haemophilia 1998; 4: 767-768.

61 Bruner AB, Joffe A, Duggan AK, Casella IF, Brandt J. Randomised study of cognitive effects of iron supplementation in non-anaemic iron-deficient adolescent girls. Lancet 1996; 348: 992-996.

62 World Health Organization (WHO). Medical Eligibility Criteria for Contraceptive Use (3rd edn). Geneva, Switzerland: WHO, 2004.

63 Faculty of Family Planning and Reproductive Health Care Clinical Effectiveness Unit. Clinical Guidance. Male and Female Condoms. January 2007. http://www.ffprhc.org.uk/ admin/uploads/999_CEUguidanceMaleFemaleCondomsJan07 .pdf [Accessed 15 July 2007].

64 Agrawal A, Robinson C. An assessment of the first 3 years' use of Implanon in Luton. J Fam Plann Reprod Health Care 2005; 31: 310-312.

65 Ylikorkala O, Viinikka L. Comparison between antifibrinolytic and antiprostaglandin treatment in the reduction of increased menstrual blood loss in women with intrauterine contraceptive devices. Br J Obstet Gynaecol 1983; 90: 78-83.

66 Inki P, Hurskainen R, Palo P, et al. Comparison of ovarian cyst formation in women using the levonorgestrel-releasing intrauterine system vs. hysterectomy. Ultrasound Obstet Gynecol 2002; 20: 322-326.

67 Faculty of Family Planning and Reproductive Health Care Clinical Effectiveness Unit. FFPRHC Guidance: Emergency Contraception (April 2003). J Fam Plann Reprod Health Care 2003; 29(2): 9-16.

\section{BOOK REVIEW}

On Chesil Beach. I McEwan. London, UK Vintage Books, 2007. ISBN: 0-09951-279-0. Price: $£ 6.99$. Pages: 176 (paperback)

Research has demonstrated that many people have sexual problems they are unable to talk about. In On Chesil Beach Ian McEwan gives us a compelling story about 'doing nothing'. He chooses a different time and he chooses Florence and Edward with their separate narratives. But it could be now. It could be anyone.

The early part of the book affords us a growing intimacy with these people. It hints at their lack of knowledge of each other. The narrative brings them separately to the moment of truth: their wedding night, both the semen and the beach. They struggle with it, step back from it, consider it, and hesitate over the opportunity and then retreat. The author allows us to experience this moment, feel their frustration, desire and silence - and to feel powerless. We know from the beginning how it will end but we wish it otherwise. We feel the pain and loss of their saying nothing. As they retreat from their marriage we lose our intimacy with them.

As readers, Ian McEwan allows us to be very skilled listeners. As doctors we too are asked to be very skilled listeners and to do more besides: to reflect with our patients, and to develop a shared understanding. Does their narrative give us any understanding? There were hints in Florence's recorded relationship with her father. Even Edward had concerns about this. We know that Florence identified a need to communicate with Edward but couldn't overcome her barrier to this. Could we have helped her understand that? Possibly, however, there is a danger that in attempting these tasks of reflection and achieving a shared understanding we lose our (therapeutic) listening skills.

This book takes hours not days. It is an

Starting in this issue with On Chesil Beach by Ian McEwan, the journal will review a work of modern fiction that has as a core theme a topic likely to be of interest and relevance to health care professionals working in the fields of sexual and reproductive health care.

The journal will announce the title to be reviewed in the next issue so that interested readers may choose to 'read along' with the reviewer and thus see whether their view of the book mirrors that of the guest reviewer. The title to be reviewed in the July issue is We Need to Talk About Kevin by Lionel Shriver (500 pages, Serpent's Tail, 2006, ISBN: 1-85242-467-2).

Finally, if any journal readers would like to offer to review an appropriate fiction title of their own choosing then they should contact the Journal Editorial Office by e-mail (journal@fsrh.org) in the first instance with details of their nominated title.

insight into non-consummation; not every case, just this one. It is an insight into people; not all people, just these people. And it gives a glimpse of the consultation, the reader-character or doctor-patient relationship and its impact on the health of our patients. And the significance of Chesil Beach? I don't know. It reminds me that colutions may not be easily accessible. Perhaps the answer for Florence and Edward, we listen to our patients and reflect with them.

Reading a novel is something wonderfully personal. There is always something more mmediate to read. Not this time. It is difficult to think that anyone reading this Journal would not benefit from reading this book. It could even be evidence of learning for next year's appraisal.

Reviewed by Alex Connan, MRCGP, MIPM

Reviewed by Alex Connan, MRCGP, 